Article

\title{
In Situ Measurement of the Junction Temperature of Light Emitting Diodes Using a Flexible Micro Temperature Sensor
}

\author{
Chi-Yuan Lee *, Ay Su, Yin-Chieh Liu, Wei-Yuan Fan and Wei-Jung Hsieh \\ Department of Mechanical Engineering, Yuan Ze Fuel Cell Center, Yuan Ze University, Taoyuan, \\ Taiwan; E-Mails: meaysu@saturn.yzu.edu.tw (A.S.); M77YCLIU@saturn.yzu.edu.tw (Y.-C.L.); \\ s975040@mail.yzu.edu.tw (W.-Y.F.); s965034@mail.yzu.edu.tw (W.-J.H.) \\ * Author to whom correspondence should be addressed; E-Mail: cylee@saturn.yzu.edu.tw; \\ Tel.: +886-3-4638800 ext2478; Fax: +886-3-4558013
}

Received: 25 May 2009; in revised form: 17 June 2009/ Accepted: 23 June 2009/

Published: 26 June 2009

\begin{abstract}
This investigation aimed to fabricate a flexible micro resistive temperature sensor to measure the junction temperature of a light emitting diode (LED). The junction temperature is typically measured using a thermal resistance measurement approach. This approach is limited in that no standard regulates the timing of data capture. This work presents a micro temperature sensor that can measure temperature stably and continuously, and has the advantages of being lightweight and able to monitor junction temperatures in real time. Micro-electro-mechanical-systems (MEMS) technologies are employed to minimize the size of a temperature sensor that is constructed on a stainless steel foil substrate (SS-304 with $30 \mu \mathrm{m}$ thickness). A flexible micro resistive temperature sensor can be fixed between the LED chip and the frame. The junction temperature of the LED can be measured from the linear relationship between the temperature and the resistance. The sensitivity of the micro temperature sensor is $0.059 \pm 0.004 \Omega /{ }^{\circ} \mathrm{C}$. The temperature of the commercial $\mathrm{CREE}^{\circledR}$ EZ1000 chip is $119.97{ }^{\circ} \mathrm{C}$ when it is thermally stable, as measured using the micro temperature sensor; however, it was $126.9^{\circ} \mathrm{C}$, when measured by thermal resistance measurement. The micro temperature sensor can be used to replace thermal resistance measurement and performs reliably.
\end{abstract}

Keywords: LED; junction temperature; MEMS; flexible micro temperature sensor 


\section{Introduction}

A light emitting diode (LED) is fabricated from p-type and n-type semiconductor materials, and an input voltage causes the LED chip to glow by combining electron holes and electrons at the $\mathrm{p}-\mathrm{n}$ junction. An LED emits various colors, which are determined by the combined semiconductors. The advantages of an LED over a light-bulb include its small volume, low temperature, low power consumption, long lifetime, fast response and environmental friendliness, whereas the standard lightbulb is limited in terms of high power consumption, ease of breakage and mercury pollution. LEDs are expected to replace all conventional light-bulbs in the next decade. Eight percent of the input power of an LED is converted to thermal energy; the area of epitaxy is very small, and the heat flux per unit area exceeds that of a central processing unit (CPU). LEDs with a high heat flux output require a strongly conducting radiator, to prevent the destruction of the package of the epitaxy [1].

The temperature of the junction affects LED performance in several ways. The light output center wavelength, spectrum, power and diode reliability all depend directly on the junction temperature, which in an LED cannot be measured using currently available instruments. Accordingly, Siegal [2] utilized the principle of a diode to indirectly measure the junction temperature in an LED. Although some investigations have determined junction temperatures by estimating thermal resistance, such an indirect method is inaccurate [3,4]. Kim [5] used thermal resistance measurement to study the highpower GaN-based light emitting diode with multichip design, and exploited the thermal design rule for packaging high-power multichip LEDs. Chen [6] measured the junction temperature using this approach, and obtained the results that were consistent with those obtained using the emission peak energy shift approach. The infrared ray scheme is an effective means of measuring the temperature of an LED, but it measures only the temperature on the top of the chip, which is not the junction temperature. Senawiratne [7] estimated used thermal resistance measurement to determine the measurement junction temperature of a light emitting diode, increasing the driving currents in increments at increments of $10 \mathrm{~mA}$ to $250 \mathrm{~mA}$. Xi [8] examined a theoretical model of the dependence of the forward voltage of a diode on junction temperature. Chen [9] applied micro-electro-mechanical systems (MEMS) techniques to develop a resistance temperature detector (RTD). Chen [10] also adopted Y-doped $\mathrm{BaZrO}_{3}$ thin films to make an RTD high-temperature sensor, and the resistance temperature detector is also applied in numerous domains [11,12]; this method is quite effective. Although a thermal resistance measurement is frequently employed, it is inaccurate because a change in the current produces a pulse, but the current can only be measured when it is stable.

This work presents a novel approach based on micro-electro-mechanical-systems (MEMS) technology to fabricate a flexible micro temperature sensor on a stainless steel foil substrate (SS-304 with a thickness of $30 \mu \mathrm{m}$ ) in order to monitor in-situ the junction temperature of a light emitting diode. This fabrication technique has the advantages of: (1) small size, (2) high sensitivity, (3) flexible but precise measurement positions, and (4) mass production. 


\section{Methodology}

\subsection{Thermal Resistance Measurement}

Previously, the junction temperature of LEDs has been determined from changes in the forward voltage [13]. Thermal resistance was measured by exploiting the fact that resistance increases with temperature, and the voltage thus declines. Figure 1 presents the circuit diagram. Thermal resistance is measured as follows: (1) Input an initial measured current $\left(\mathrm{I}_{\mathrm{M}}\right)$ and measure the initial voltage $\left(\mathrm{V}_{\mathrm{F} 0}\right)$; (2) Input a higher heating current $\left(\mathrm{I}_{\mathrm{H}}\right)$ until the temperature is stable; (3) Change the measured current $\left(\mathrm{I}_{\mathrm{M}}\right)$ rapidly, and measure the voltage $\left(\mathrm{V}_{\mathrm{FSS}}\right)$ after heating; (4) Compare $\mathrm{V}_{\mathrm{F} 0}$ and $\mathrm{V}_{\mathrm{FSS}}$ following calibration to yield the temperature of the LED chip, as shown in Figure 2.

Although measurements of thermal resistance are useful, this approach cannot always be applied to measure temperature, and a pulse is produced when the current is changed. The pulse affects the voltage, destabilizing the measured temperature.

Figure 1. Circuit illustration of thermal resistance measurement technology.

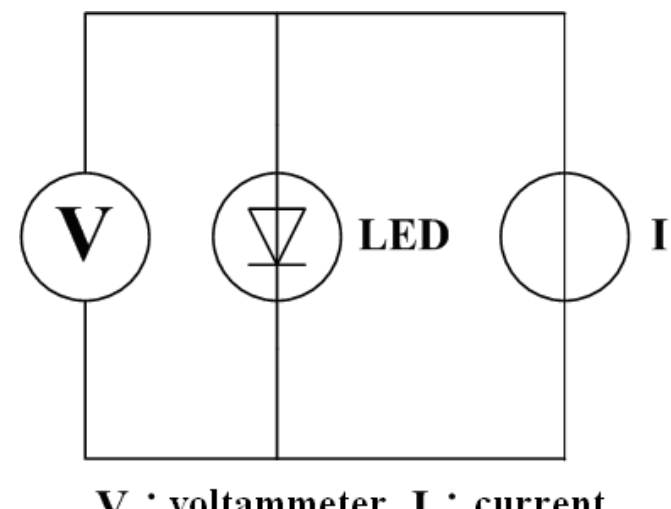

Figure 2. Measuring procedure of thermal resistance measurement technology.
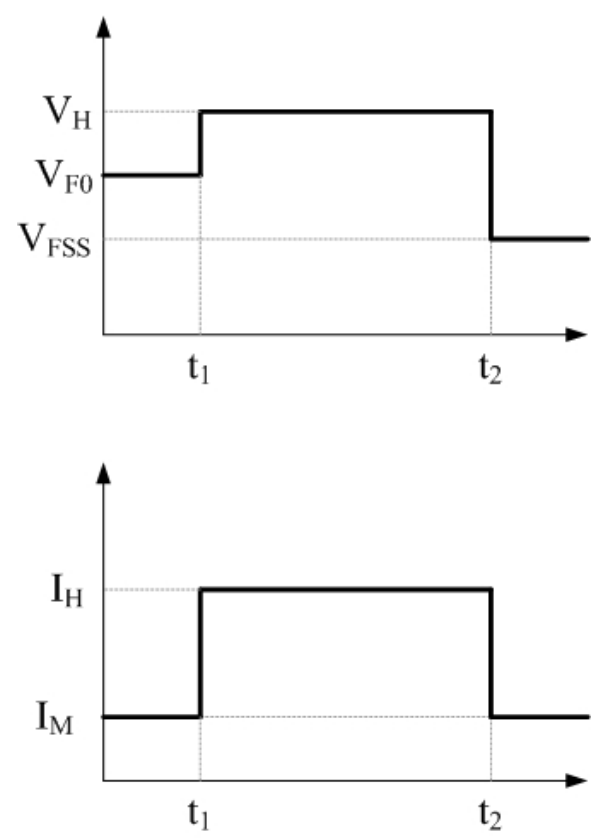


\subsection{Resistance Temperature Detector}

In this work, the temperature sensor was a resistance temperature detector (RTD). As the environmental temperature increases, the resistance of the RTD also increases, because a metal conductor has a positive temperature coefficient (PTC). When the temperature of the RTD varies linearly, the relationship between the measured resistance and the change in temperature can be expressed as:

$$
R_{t}=R_{i}\left(1+\alpha_{T} T\right)
$$

where $R_{t}$ denotes the resistance at $t^{\circ} \mathrm{C} ; R_{i}$ is the resistance at $i{ }^{\circ} \mathrm{C}$, and $\alpha_{T}$ is the sensitivity $\left(1 /{ }^{\circ} \mathrm{C}\right)[14]$.

Equation (1) can be rewritten as:

$$
\alpha_{T}=\frac{R_{t}-R_{i}}{R_{i}(\Delta T)}
$$

\section{Fabrication of Flexible Micro Temperature Sensor}

The frame of the LED is a very important gateway for heat conduction for the LED chip, so a medium is installed between the frame of the LED and the LED chip to increase thermal resistance. In this investigation, micro temperature sensors were fabricated on a stainless steel foil substrate (SS-304 with $30 \mu \mathrm{m}$ thickness), and aluminum nitride (AlN) was applied as an insulation layer because of its excellent insulation and high thermal conductivity properties.

Figure 3. Fabrication of flexible micro temperature sensor.

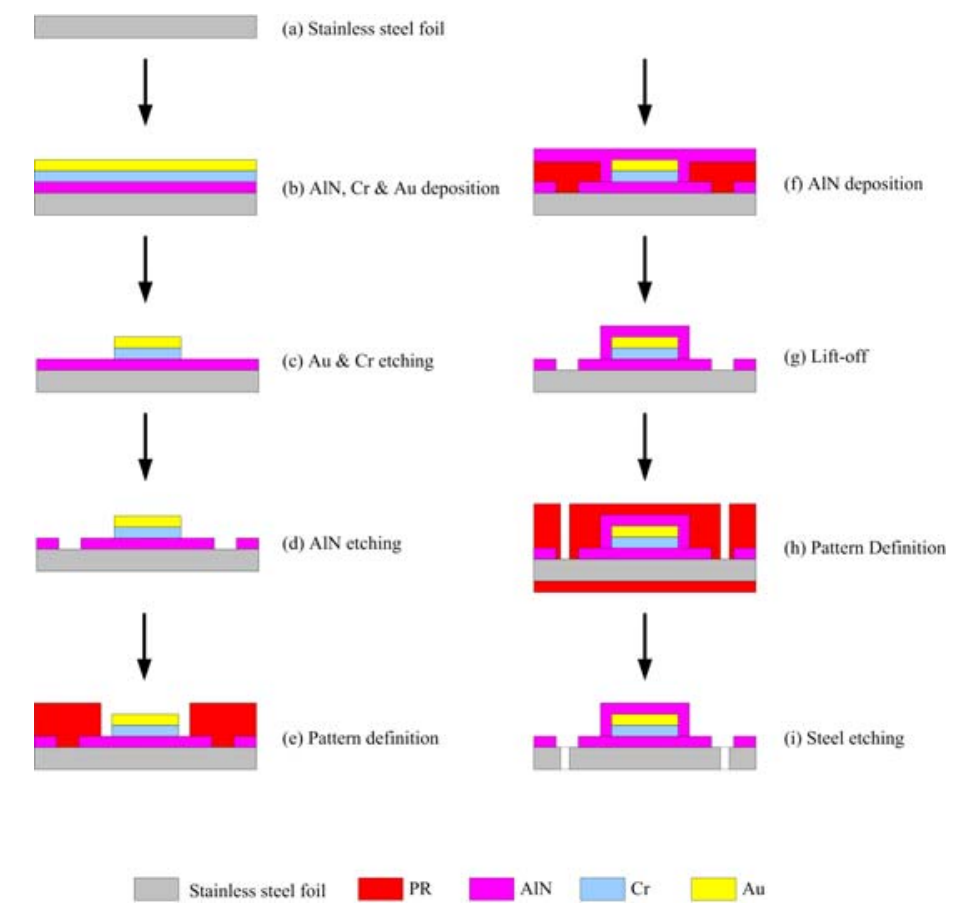

The total line-length of the sensing area of the micro temperature sensor was $1,200 \mu \mathrm{m}$, and its planar dimensions were $230 \times 90 \mu^{2}$. Figure 3 presents the fabrication of a flexible micro temperature sensor using the following steps: first, sulfuric acid and hydrogen peroxide are employed to clean the 
stainless steel foil; the photoresist is then spun and lithography performed to define the outline of the micro temperature sensors. Then, aluminum nitride (AlN) is sputtered as a bottom insulation layer, and the lift-off method is used to remove the photoresist. An E-beam evaporator is then applied to evaporate chromium ( $\mathrm{Cr}$ ) as an adhesive layer between $\mathrm{AlN}$ and gold, and evaporated gold ( $\mathrm{Au}$ ) is used to form micro temperature sensors by wet etching. Finally, another aluminum nitride (AlN) with a thickness of $2,500 \AA$ is sputtered as a top insulation layer, and the micro temperature sensors are connected via an $\mathrm{Al}$ wire.

\section{Results and Discussion}

In Figure 4, the micro temperature sensor is set between a $1 \mathrm{~W}$ LED chip and a frame, and an input current with $350 \mathrm{~mA}$ is passed through the LED, causing it to glow. After the temperature has stabilized, the resistance of the micro temperature sensor is measured using an ohmmeter, and compared to the calibration curve of the micro temperature sensor, to determine the temperature; this result is compared the thermal resistance measurement. The temperature sensor requires a protective layer, so an insulation layer was deposited on the temperature, but the insulation layer was very thin, and the thermal gradient was small to ignore.

Figure 4. Illustration of micro temperature sensor in LED.

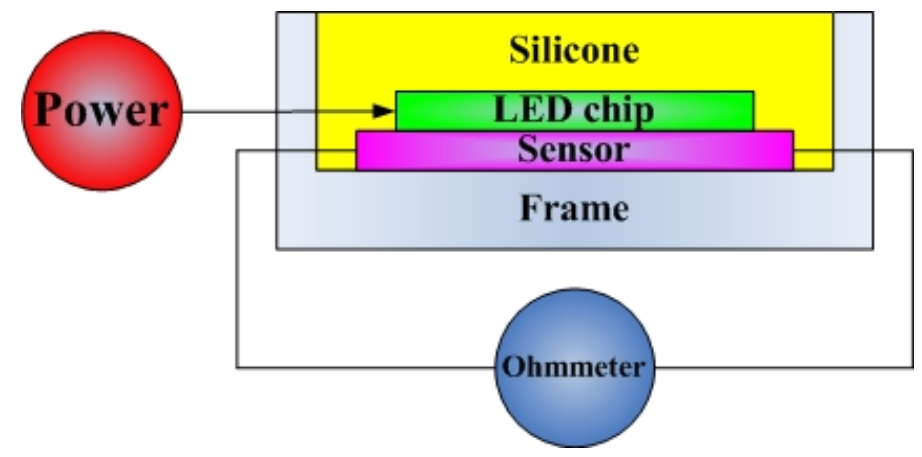

Figures 5 and 6 display an LED with a micro temperature sensor and a photograph of the micro temperature sensor, respectively. Figure 7 depicts the calibration system of a micro temperature sensor. The micro temperature sensor is placed in an oven, and the resistance of the micro temperature sensor is measured using an ohmmeter. Figure 8 plots the two calibration curves of the micro temperature sensor; the result demonstrates that temperature is almost linearly related to resistance and the sensitivity was $0.059 \pm 0.004 \Omega /{ }^{\circ} \mathrm{C}$, temperature sensor accuracy was defined based on the temperature in the accuracy range $\left(0.5^{\circ} \mathrm{C}\right)$ of programmable temperature chamber.

The junction temperature of the LED can be determined from the voltage based on the theory of thermal resistance measurement. A CREE® EZ1000 chip and input currents of $100 \mathrm{~mA}$ and $350 \mathrm{~mA}$ were used. The data obtained by thermal resistance measurement differ from those obtained using a micro temperature sensor, as shown in Table 1 . The temperature obtained using the micro temperature sensor was $5.18^{\circ} \mathrm{C}$ lower than that obtained by thermal resistance measurement at $100 \mathrm{~mA}$, and $6.93 \mathrm{C}$ lower at $350 \mathrm{~mA}$. The difference increased with temperature. 
Figure 5. High-power LED with micro temperature sensor.

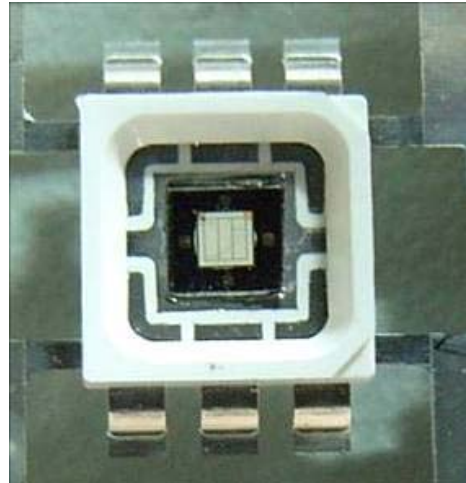

Figure 6. Optical microscopic photograph of micro temperature sensor.

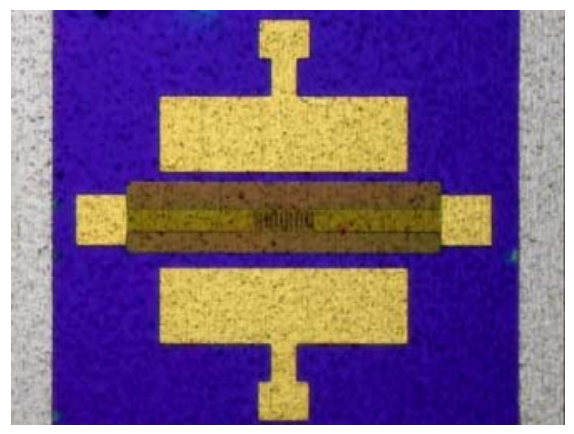

Figure 7. Calibration system of micro temperature sensor.

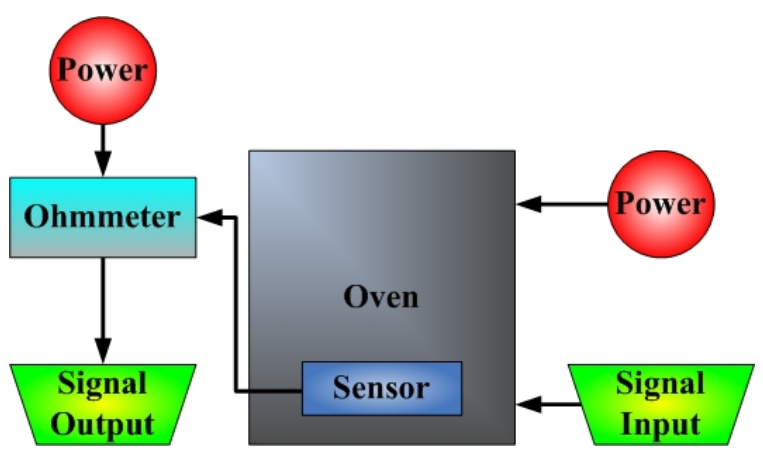

Figure 8. Calibration curve of the micro temperature sensor.

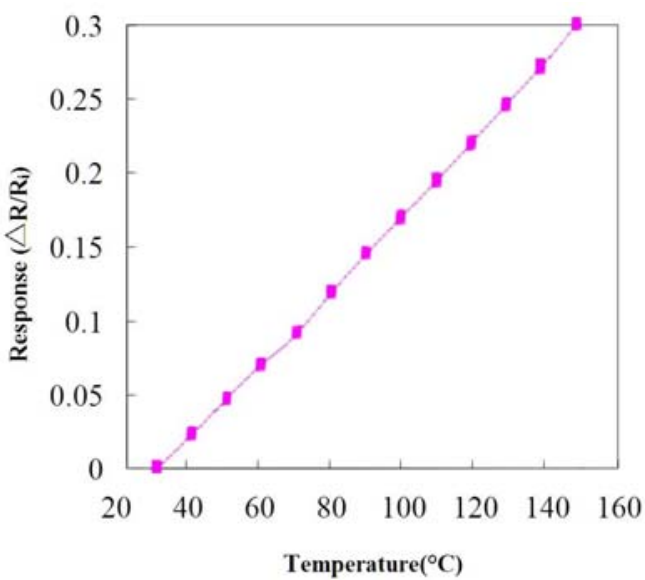


Table 1. Difference between measurements made using thermal resistance measurement technology and micro temperature sensor.

\begin{tabular}{cccc}
\hline \multirow{2}{*}{$\begin{array}{c}\text { Operating } \\
\text { current }\end{array}$} & $\begin{array}{c}\text { Thermal resistance } \\
\text { measurement }\end{array}$ & \multicolumn{2}{c}{ Micro temperature sensor } \\
\cline { 2 - 4 } & Temperature $\left({ }^{\circ} \mathbf{C}\right)$ & Resistance $(\boldsymbol{\Omega})$ & Temperature $\left({ }^{\circ} \mathbf{C}\right)$ \\
\hline $100 \mathrm{~mA}$ & 52.3 & 23.82 & 47.12 \\
$350 \mathrm{~mA}$ & 126.9 & 27.91 & 119.97 \\
\hline
\end{tabular}

\section{Conclusions}

In this work, a flexible micro temperature sensor that could be set between an LED chip and frame was developed, and $30 \mu \mathrm{m}$-thick stainless steel foil was used to conduct heat between the LED chip and the frame. Flexible micro temperature sensors were fabricated using micro-electro-mechanicalsystems (MEMS) fabrication technique. The sensors have the advantages of: (1) small size, (2) high sensitivity, (3) flexible but precise measurement positions, and (4) mass production. A future study will adopt flexible micro temperature sensors to evaluate the operating parameters and thus improve the design and performance of LEDs.

\section{Acknowledgements}

This work was accomplished with much needed support and the authors would like to acknowledge the financial support of this research from the National Science Council of R.O.C. through grant NSC 96-2221-E-155-054. The authors also like to thank the YZU NENS Common Lab and NTU NMES Research Center for providing access to their research facilities.

\section{References}

1. Su, A.; Liu, Y.C.; Chen. C.Y. Thermal diffusion analysis for LED module. Heat Tran. Asian Res. 2007, 36, 449-458.

2. Siegal, B. Measurement of junction temperature confirms package thermal design. Laser Focus World 2003, 11, S12-S14.

3. Shih, K. LED junction temperature test unit operating manual. Acorn Technology 2003.

4. Hu, J.; Yang, L.; Shin, M.W. Mechanism and thermal effect of delamination in light-emitting diode packages. Microelectr. J. 2007, 38, 157-163.

5. Kim, L.; Shin, M.W. Thermal resistance measurement of LED package with multichips. IEEE Trans. Compon. Packaging T. 2007, 30, 632-636.

6 Chen, N.C.; Wang, Y.N.; Tseng, C.Y.; Yang, Y.K. Determination of junction temperature in AlGaInP/GaAs light emitting diodes by self-excited photoluminescence signal. Appl. Phys. Lett. 2006, 89, 101114-101116. 
7. Senawiratne, J.; Li, Y.; Zhu, M.; Xia, Y.; Zhao, W.; Detchprohm, T.; Chatterjee, A.; Plawsky, J.L.; Wetzel, C. Junction temperature measurements and thermal modeling of GaInN/GaN quantum well light-emitting diodes. J. Elec. Mat. 2008, 37, 607-610.

8. Xi, Y.; Schubert. E.F. Junction-temperature measurement in GaN ultraviolet light-emitting diodes using diode forward voltage method. Appl. Phys. Lett. 2004, 85, 2163-2165.

9. Chen, L.T.; Lee, C.Y.; Cheng, W.H. MEMS-based humidity sensor with integrated temperature compensation mechanism. Sens. Actuat. A 2008, 147, 522-528.

10. Chen, X.X.; Rieth, L.; Miller, M.S.; Florian S. High temperature humidity sensors based on sputtered Y-doped $\mathrm{BaZrO}_{3}$ thin films. Sens. Actuat. B: Chem. 2009, 137, 578-585.

11. Lee, C.Y.; Lee, S.J.; Shen, C.C.; Yan, W.M.; Weng, F.B.; Jung, G.B.; Lin, C.H. Fabrication of flexible micro-sensors and flow field of stainless steel-based micro-reformer by micro-electromechanical-systems process. J. Power Sources 2009, 193, 150-154.

12. Lee, C.Y.; Hsieh, W.J.; Wu, G.W. Embedded flexible micro-sensors in MEA for measuring temperature and humidity in a micro-fuel cell. J. Power Sources 2008, 191, 237-243.

13. Han, J.H.; Park. S.W. Theoretical and experimental study on junction temperature of packaged Fabry-Perot laser diode. IEEE Trans. Device. Mater. Reliab. 2004, 4, 292-294.

14. Wilson, J.S. Sensor technology handbook. Butterworth-Heinemann: Boston, MA, USA, 2004.

(C) 2009 by the authors; licensee Molecular Diversity Preservation International, Basel, Switzerland. This article is an open-access article distributed under the terms and conditions of the Creative Commons Attribution license (http://creativecommons.org/licenses/by/3.0/). 